\title{
Correction to: $\mathrm{BiVO}_{4}(010) / \mathrm{rGO}$ Nanocomposite and Its Photocatalysis Application
}

\author{
Lianwei Shan ${ }^{1}{ }^{1}$. Jingjing $\mathrm{Bi}^{1}$. Changhui $\mathrm{Lu}^{1} \cdot$ Yanwei Xiao $^{1}$
}

Published online: 13 November 2018

○) Springer Science+Business Media, LLC, part of Springer Nature 2018

\section{Correction to: \\ Journal of Inorganic and Organometallic Polymers and Materials \\ https://doi.org/10.1007/s10904-018-0990-9}

The article "BiVO $4(010) / \mathrm{rGO}$ Nanocomposite and Its Photocatalysis Application", written by Lianwei Shan, Jingjing $\mathrm{Bi}$, Changhui Lu and Yanwei Xiao, was originally published electronically on the publisher's internet portal (currently
SpringerLink) on 5 October 2018 with open access. With the author(s)' decision to step back from Open Choice, the copyright of the article changed on November 2018 to (C) Springer Science + Business Media, LLC, part of Springer Nature 2018 and the article is forthwith distributed under the terms of copyright.

The original article has been corrected.

The original article can be found online at https://doi.org/10.1007/ s10904-018-0990-9.

Lianwei Shan

shlw0531@163.com

1 School of Materials Science and Engineering, Harbin University of Science and Technology, Harbin 150040,

China 